\title{
Biophysical Reviews-A call to young biophysicists
}

\author{
Damien Hall ${ }^{1,2}$
}

Received: 20 May 2021 / Accepted: 24 May 2021 / Published online: 28 May 2021

(C) International Union for Pure and Applied Biophysics (IUPAB) and Springer-Verlag GmbH Germany, part of Springer Nature 2021

\begin{abstract}
This Editorial for Volume 13, Issue 3 of Biophysical Reviews begins with a summary of the Issue contents. This is then followed by a discussion of some additional matters important to the journal. In particular, this Editorial offers some thoughts as to what constitutes a good scientific Commentary before announcing the call for nominations for the 'The 2022 Michèle Auger Award for Young Scientists' Independent Research'.
\end{abstract}

\section{Biophysical Reviews and IUPAB}

Biophysical Reviews is the topical review journal of the International Union for Pure and Applied Biophysics (IUPAB). From its first article in 2009 (Garnier 2009), Biophysical Reviews has endeavored to provide a service to the international biophysical community in the following ways:

(i) facilitating the publication of review articles by experts in the field on topics comporting to the general categories of biophysics, structural biology, and molecular biology;

(ii) providing a publishing forum which is accessible (both financially and in terms of human contact) to scientists located in all regions of the world;

(iii) assisting, where possible, with IUPAB's mandated mission of enhancing international cooperation in biophysics-based research and biophysical education.

To carry out these aims, the journal utilizes an international Editorial Board comprised of biophysicists with a range of expertise. Editorial Board Members regularly invite deserving and capable scientists within their geographical region or professional area of interest to contribute review articles, scientific letters or commentaries. When required, Editorial Board

Damien Hall

hall.damien@staff.kanazawa-u.ac.jp; damienhall30@gmail.com

1 WPI Nano Life Science Institute, Kanazawa University, Kakumamachi, Kanazawa, Ishikawa 920-1164, Japan

2 Department of Applied Physics, Aalto University, FI-00076 Aalto, Finland
Members also act as expert scientific reviewers, offering a critique of submitted manuscripts within their areas of competence.

\section{Precis of current Issue contents}

The first duty of this Editorial is to provide a precis of its contents. Issue 3 is divided into two sections, the front matter (which can feature Editorials, Commentaries and Letters) and the body (which contains topical Reviews). We begin our summary with the front matter articles before moving on to describe the scientific review articles.

Immediately following the current Editorial (Hall 2021a) is a second sub-editorial that continues the journal's 'Meet the Biophysical Reviews Editors' series, this time featuring Prof. Jeremy R.H. Tame of Yokohama City University, Japan (Tame 2021). Jeremy is a very interesting scientist that I had the good fortune to meet in Japan nearly a decade ago. With an impressive pedigree in the field of protein crystallography (involving numerous Nobel Prize winners), Jeremy combines a keen intellect with a deep understanding of scientific history and a liberal dash of humor to guide his research and both inform and entertain his readers (Tame 2019; Mylemans et al. 2021). He has been an active Biophysical Reviews' Editorial Board Member both in terms of contributing to the journal (Park and Tame 2017) and in assisting with the journal's broader goals of promoting internationalization of biophysical research. As an example of this latter point, Jeremy was one of the Special Issue Editors of the journal's first National Biophysical Society Partnership Program (Komatsuzaki et al. 2020; Hall 2020a). The mini-scientific and personal biography provided by Jeremy is eminently 
readable and its inclusion of a number of important ethical and practical dilemmas should make it compulsory reading for both scientists in training and those carrying out the supervision (Tame 2021).

The third article is a scientific Commentary contributed by the President of IUPAB, Prof. Marcelo Morales (Morales 2021). In this Commentary, Marcelo outlines the history, constitution and aims of IUPAB. Reflecting on his period of tenure as the head of the organization, he also describes his own pathway as a scientist and the steps that led to his election to the position of President. Marcelo has genuinely done a great job of steering IUPAB through the difficulties associated with the pandemic. The journal thanks him for both his continuing service and his informative contribution about IUPAB - the journal's parent organization (Morales 2021).

The fourth front matter article is an announcement of a call for contributions to an upcoming Special Issue (SI) on cardiovascular mechanobiology (Iskratsch and Swiatlowski, 2021). Seeking to collate and present a range of review articles describing both the state of the art and the newest insights into the role of mechanical forces in cardiovascular development, physiology, and disease, the two SI Editors, Dr. Thomas Iskratch and Dr. Pamela Swiatlowski of Queen Mary University of London, have already secured a bevy of expert contributions. However the SI Editors can still be contacted by any interested parties wishing to join and make a contribution to the Issue (Swiatlowski and Iskratsch 2021).

The next two articles appearing in the front matter section are session Commentaries describing two subgroup meetings that took place at the recent 2021 virtual US Biophysical Society (Schlick and Bishop 2021; Cortassa and Aon 2021). Respectively describing the speakers and topics of the Multiscale Genome Organization (MGO) subgroup and the Bioenergetics, Mitochondria and Metabolism (BMM) subgroup, these two session commentaries provide an intimate and insightful look at the topics explored during these one day symposia written by the session chairs (and organizers) of the events themselves. As part of a recurring (yearly) subgroup event, the authors can be contacted regarding potential participation in 2022 and beyond (Schlick and Bishop 2021; Cortassa and Aon 2021).

Moving on to the scientific review section, we note that regular Issues have no unifying theme. Even with acknowledgement of this point, it would be fair to say that the six review articles appearing in this Issue of the journal are extremely diverse in terms of subject matter. The first of these contributed Reviews, submitted by two scientists from Russia, deals with the application of analytical soliton theory (unique/ individual wave motion) to the propagation of open or 'breathing' states within DNA (Yakushevich and Krasnobaeva 2021). Presenting numerous approximate solutions of the McLaughlin-Scott equation (McLaughlin and Scott 1978), the authors present an interesting alternative approach to the simulation of DNA dynamics. In a computational environment sometimes dominated by the 'wiggling and jiggling' of short time scale molecular dynamics-based studies, this review article describing the authors' substantial efforts in modelling DNA open states associated with transcription and repair processes is a virtual 'breath' of fresh air (Yakushevich and Krasnobaeva 2021).

The second Review contribution, from scientists located in Greece and the UK, tackles the topic of cancer mechanobiology (Vasilaki et al. 2021). Taking a tripartite viewpoint of the subject, the Review first discusses differences in mechanical properties (such as elasticity and Poisson's ratio) of cancerous versus non-cancerous cells. It then moves on to review the outside-to-inside biophysical transduction machinery responsible for converting the different mechanical forces experienced by a cancer cell (during its progression through the metastatic cycle) into biochemical outcomes. Finally, the Review discusses the inside-tooutside transduction principles by which the cancer cell can exert mechanical force on its environment (such as through traction forces acting on other cell surfaces) in response to biochemical changes occurring with the cell. With extremely clear exposition, this review article on the mechanobiology of cancer will undoubtedly become influential within the field (Vasilaki et al. 2021).

Contributed from a multi-disciplinary team of scientists based within the Indian state of Karnataka, the third review article examines literature associated with two related areas of medical biophysics (Lukose et al. 2021). The first of these is the predictive and diagnostic potential of the biomarkers present within saliva for accurate assessment of disease. The second area of inquiry concerns a review of modern integrated optical procedures ('photonics') capable of directly determining the composition and concentration of the saliva biomarkers. Integrated optics typically refers to wave-guided light manipulated under the condition of total internal reflectance (e.g. fiber optics). Focusing principally on measurement procedures amenable to use in a waveguide format (such as surface plasmon resonance (SPR)-based analysis of local refractive index, SPRenhanced fluorescence, attenuated total reflection Fourier transform infra-red spectrophotometry (ATR-FTIR), and surfaceenhanced Raman spectroscopy (SERS)), the authors indicate how extreme levels of detection sensitivity can be achieved. A further interesting aspect of the present review article is its discussion of modern machine learning approaches for analyzing biomarker profiles (Lukose et al. 2021).

Expressing a personal opinion, I found the fourth article (Hameed and Manivasagam 2021) to be particularly fascinating and well worth of a second read. Covering a number of topics, the authors first review the physical and biochemical factors regulating the structure of collagen gels (e.g. hydration, $\mathrm{pH}$, protein self-association). They then describe the mechanical interactions between cells and the collagen gel in the 
form of elastic deformation/compression as well as the formation of tight specific linkages associated with cell traction. The authors discuss how mechanical forces exerted by collagen can alter cell differentiation and lineage-fate outcomes. They then discuss the converse case- how forces exerted by the cell on the collagen gel, either directly (via pushing or pulling) or indirectly (via release of gel severing enzymes, local wetting or dehydration effects), can alter the structure of the gel. Synthesizing these interlinked phenomena, the authors then review the area of 'cell origami' the concept that purposeful plating of cells within a gel matrix could rationally bend and fold the matrix to produce a desired structure as per an origami-like design principle (Kuribayashi-Shigetomi et al. 2012; Hameed and Manivasagam 2021).

The fifth Review, submitted by a collection of medical scientists located in Morocco, Benin ${ }^{1}$ and the UK (Jossou et al. 2021), concerns the very practical question of optimal experimental recording protocols for electrohysterographybased measurements of pregnant women's contractions. Tackling the subject from a remote medicine perspective (where hospitals are frequently absent and complicated and expensive equipment is often hundreds of kilometers away), the authors review over approximately fifty published studies of electrohysterographical measurements to determine a minimal consensus protocol, in terms of electrode placement and circuit design, of the much simpler and more transportable electrical measurement apparatus (Jossou et al. 2021).

The final review article of Issue 6 deals with the topic of ultrasound-assisted enhancement of enzyme function (Khan et al. 2021). Approaching the subject from a biotechnological process point of view, the authors discuss how ultrasound can regulate enzyme function directly via physical factors associated with ultrasound intensity, ultrasonic reactor design, and importance of a duty cycle. The authors also explore the alteration of enzyme function due to indirect ultrasound influence on chemical/mechanistic factors associated with solution $\mathrm{pH}$, water decomposition via sonolysis, active enzyme concentration, ultrasound determined reactant solubility and the 'fine tuning' of competition between protein aggregation and unfolding (Khan et al. 2021).

Having described the Issue contents, we now turn to a discussion of matters important to readers of the journal.

\section{A well-written Commentary}

Biophysical Reviews accepts five general types of submission formats.

- $\quad$ Short Review (3000-4000 words, 3 figures)

\footnotetext{
${ }^{1}$ Of particular note this manuscript represents the journal's first article from Benin.
}

- Long Review (10,000 words, $\sim 10$ figures)

- Letter ( $\sim 400-800$ words on a scientific topic or scientific event of note)

- Commentary ( 200-500 words on an event, happening or opinion)

- Editorial (usually written by a member of the Editorial Board)

As the current Issue features four quite diverse Commentaries, it is appropriate here to expand upon this particular submission format and describe what type of information can be conveyed within it. A Biophysical Reviews' Commentary usually comports to one of three different types.

(i) Announcement type: Most typically this form of Commentary is used to describe the planned occurrence of a major scientific event sometime in the future. This forward-looking type of Commentary is particularly useful to promote a call for contributions to an upcoming Special Issue (e.g. as for Swiatlowski and Iskratsch 2021) or to describe a planned major scientific meeting or event sometime in the future, as for the upcoming IUPAB Congress (Itri et al. 2021).

(ii) Session type: This rearward-looking format is typically used to summarize the events of a short symposium or a conference session that occurred sometime in the recent past (e.g. as for Schlick and Bishop 2021; Cortassa and Aon 2021). These types of Commentary can be particularly useful for session chairpersons as they allow for greater explanation of the goals of the session, the background of the speakers and what was actually talked about in the session (as speakers topics can sometimes change on the day). They also provide a very useful summary space that allow the session chairpersons to synthesize the different talks and point out open questions arising from the session.

(iii) Opinion or description type: This commentary style is ideal for the communication of a personal story or the relaying of procedural or societal news of likely interest to the readers of Biophysical Reviews. The current Issue (Issue 3 ) and this years' Issue 1 both contain good examples of such commentary formats that relay information about IUPAB from the Secretary General and the President of the organization (Gómez-Fernández 2021; Morales 2021). In previous Issues, this opinion/ description format has also been used to provide a background perspective to an SI theme (Pérez and ESB Council 2020; Welton 2018) or comment on a scientist who is the subject of a festschrift (Berry 2020; Rossmann 2018; Laue 2016; Minton 2016).

With this information in hand, the journal actively encourages the biophysical community to make use of 
Commentaries to better facilitate international cooperation and to promote biophysics-related education and research.

\section{Call for nominations for the 2022 MA Award}

In late 2018, Canadian biophysicist Prof. Michèle Auger, a long-time Editorial Board Member of Biophysical Reviews, sadly lost her battle with cancer (IUPAB 2019). As a sign of the journal's esteem for Michèle, a perpetual annual award was established to honor her name and memory at the 2019 Editorial Board Meeting.

The 'Michèle Auger Award for Young Scientists' Independent Research' is granted each year to a single candidate performing biophysical research who, at the time of application, is under 40 years of age. The award consists of a plaque and a free personal subscription to the journal along with an invitation to submit a single author review article to Biophysical Reviews. The winner's published Review will carry a short foreword about the life of Professor Michèle Auger, along with her work associated with teaching and training the next generation of biophysical scientists. First run in 2020, the two previous winners were Assistant Professor Alexandra Zidovska (2020) and Associate Professor Jorge Alegre-Cebollada (2021). Their public research details can be found below.

- Assist. Prof. Alexandra Zidovska (winner 2020) Web: https://www.physics.nyu.edu

- Assoc. Prof. Jorge Alegre-Cebollada (winner 2021) Web: https://www.cnic.es/en/jorge-alegre-cebollada

Nominations for the upcoming 2022 award can be made in the form of a candidate's one page curriculum vitae, along with five original manuscripts, to be submitted by email to either the Chief Editor, or any one of the Biophysical Reviews' Executive Editors, prior to October $31^{\text {st }} 2021$. As for the previous years, judging will be carried out by a special committee assembled predominantly from the Biophysical Reviews' Editorial Board, with this assembly taking place after the submission deadline. Results will be announced in late December, with the winner's single author Review to be published in a later Issue the following year. Nominations can be made via email in the form described above to any of the following.

\section{Chief Editor}

D. Hall hall.damien@staff.kanazawa-u.ac.jp Japan.

\section{Executive Editors}

- S. Harding_steve.harding@nottingham.ac.uk, UK

- J.W.K. Ho_jwkho@hku.hk, Hong Kong, China

- R. Itri-itri@if.usp.br, Brazil

- N. R. Jagannathan-jagan1954@hotmail.com, India

- K. Nagayama—nagayama@nips.ac.jp, Japan

- W. Olson—wilma.olson@rutgers.edu, USA

- G. Rivas_-grivas@cib.csic.es, Spain

For those interested in entering (or nominating another) additional details about the judging and selection of winners for the previous years' competitions can be found in the following references: Hall (2020b, 2020c, 2020d); Hall (2021b, 2021c). The 2020 winner's published review article can be found here (Zidovska 2020) with the 2021 winner's published review article set to appear in the upcoming Issue 4.

\section{Concluding remarks}

More can be learnt about the journal at its official Springer Nature website and also from selected descriptive content released on its social media pages on Twitter and YouTube (Hall 2017; Hall 2020d).

Web: https://www.springer.com/journal/12551

Twitter: @BiophysicalRev1

YouTube: www.youtube.com/channel/UCzG_ 5MWmnrB2UBibtxs2DuA

Potential authors interested in submitting an article to Biophysical Reviews are encouraged to first raise the matter with either the Chief Editor or their local Executive or Editorial Board Member. After discussion on the suitability of their article, a timetable for their submission will be arranged in conjunction with the professional officers of the journal. 
Acknowledgements I would like to thank Dr. Meran Lloyd-Owen and Prof. Adam S. Foster for comments made on an earlier draft of this manuscript. DH acknowledges funding associated with the receipt of a 'Tokunin' Assistant Professorship carried out at the WPI-Center for Nano Life Science, Kanazawa University. DH also acknowledges the University of Aalto, for an appointment to their Affiliated Researcher Program carried out within the Department of Applied Physics.

\section{Declarations}

Conflict of interest The author declares no competing interests.

\section{References}

Berry DA (2020) Recollections of my Ph. D. research in Professor Cris dos Remedios' laboratory. Biophysical Reviews 12:749-751. https://doi.org/10.1007/s12551-020-00707-3

Cortassa S, Aon MA (2021) From chronology to the biology of aging, and its tuning by mitochondrial health: Overview of the Bioenergetics, Mitochondria and Metabolism subgroup Symposium at the 2021 Virtual $65^{\text {th }}$ Annual Meeting of the Biophysical Society. Biophysical Reviews 13 (3). https://doi.org/ 10.1007/s12551-021-00808-7

Garnier J (2009) Editorial. Biophysical Reviews 1(1):1-1. https://doi.org/ 10.1007/s12551-008-0001-4

Gómez-Fernández JC (2021) Greetings from IUPAB Secretary General. Biophysical Reviews 13(1):13-12. https://doi.org/10.1007/s12551021-00785-x

Hall D (2017) Innovations in publication: free sharing of all Biophysical Reviews' content. Biophysical Reviews 9:67-68. https://doi.org/10. 1007/s12551-017-0253-y

Hall D (2020a) Biophysical Reviews' national biophysical society partnership program. Biophysical Reviews 12(2):187-192. https://doi. org/10.1007/s12551-020-00622-7

Hall D (2020b) A new decade for Biophysical Reviews and a look into the future of biophysics. Biophysical Reviews. 12:1-7. https://doi. org/10.1007/s12551-020-00622-7

Hall D (2020c) Biophysical Reviews - Quantitative analysis of biological phenomenon. Biophysical Reviews. 12:601-605. https://doi.org/10. 1007/s12551-020-00702-8

Hall D (2020d) Biophysical Reviews: a Q1 ranked journal in biophysics and structural biology. Biophysical Reviews 12:1085-1089. https:// doi.org/10.1007/s12551-020-00764-8

Hall D. (2021a) Biophysical Reviews - A call to young biophysicists. 13(3). https://doi.org/10.1007/s12551-021-00810-z

Hall D (2021b) Biophysical Reviews: slowly getting back to 'normal'? Biophysical Reviews 13(2):161-165. https://doi.org/10.1007/ s12551-021-00797-7

Hall D (2021c) Biophysical Reviews - the IUPAB journal tasked with advancing biophysics. Biophysical Reviews 13(1):1-6. https://doi. org/10.1007/s12551-021-00788-8

Hameed P, Manivasagam G. (2021) An overview of bio-actuation in collagen hydrogels: a mechanobiological phenomenon. Biophysical Reviews 13(3). https://doi.org/10.1007/s12551-02100804-X

Itri R, Baptista MS, Garratt R, da Costa Filho AJ (2021) Announcing the call for the Special Issue on the 20th International Congress of the International Union of Pure and Applied Biophysics (IUPAB) virtual meeting, October 2021. Biophysical Reviews 13(2):171172. https://doi.org/10.1007/s12551-021-00796-8

IUPAB (2019) Newsletter, issue 70 (February). http://iupab.org/2018/11/ 06/obituary-michele-auger-former-iupab-councilor/
Jossou TR, Et-tahir A, Tahori Z, El Ouadi A, Medenou D, Bybi A, Fagbemi L, Sbihi M, Piaggio D (2021) Electrodes in external electrohysterography: a systematic literature review. Biophysical Reviews 13(3) Current Issue. https://doi.org/10.1007/s12551-02100805-w

Khan A, Beg MR, Waghmare P (2021) Intensification of biokinetics of enzymes using ultrasound assisted methods: A critical review. Biophysical Reviews 13(3). https://doi.org/10.1007/s12551-02100806-9

Komatsuzaki T, Nakamura H, Tame J, Yanaka S, Nagai T, Nagayama K (2020) Editorial for the Special Issue of Biophysical Reviews focused on the Biophysical Society of Japan with select scientific content from the $57^{\text {th }}$ BSJ annual meeting, Miyazaki, Japan. Biophysical Reviews. Biophysical Reviews 12(2):183-185. https://doi.org/10.1007/s12551-020-00691-8

Kuribayashi-Shigetomi K, Onoe H, Takeuchi S (2012) Cell origami: selffolding of three-dimensional cell-laden microstructures driven by cell traction force. PloS one 7(12):e51085. https://doi.org/10.1371/ journal.pone.0051085.g001

Laue T (2016) Charge matters. Biophysical Reviews. 8:287-289. https:// doi.org/10.1007/s12551-016-0229-3

Lukose J., Sanoop-Pavithran M., Mithun N., Barik A.K., Pai K.M., Unnikrishnan V.K., George S.D., V.B. Kartha and S. Chidangil (2021) Photonics of Human Saliva: Potential Optical Methods for the Screening of Abnormal Health Conditions and Infections. Biophysical Reviews 13(3). https://doi.org/10.1007/s12551-02100807-8

McLaughlin DW, Scott AC (1978) Perturbation analysis of fluxon dynamics. Physical Reviews A 18:1652. https://doi.org/10.1103/ PhysRevA.18.1652

Minton AP (2016) Big ideas from "small science". Biophysical Reviews 8(4):285-286. https://doi.org/10.1007/s12551-016-0225-7

Morales M.A. (2021) IUPAB - Serving the international biophysics community. Biophysical Reviews. 13(3). https://doi.org/10.1007/ s12551-021-00802-Z

Mylemans B, Voet AR, Tame JR (2021) The Taming of the Screw: the natural and artificial development of $\beta$-propeller proteins. Current Opinion in Structural Biology 68:48-54. https://doi.org/10.1016/j. sbi.2020.11.009

Park SY, Tame JR (2017) Seeing the light with BLUF proteins. Biophysical reviews 9(2):169-176. https://doi.org/10.1007/ s12551-017-0258-6

Pérez MA, ESB Council (2020) Introduction to the European Society of Biomechanics. Biophysical Reviews 11:671-672. https://doi.org/ 10.1007/s12551-019-00586-3

Rossmann MG (2018) My happy years of collaboration with Fumio Arisaka. Biophysical reviews 10(2):139-140. https://doi.org/10. 1007/s12551-017-0359-2

Schlick T. and Bishop T.C. (2021) MGO on the go: Multiscale genome symposium - annual biophysical society meeting 2021. Biophysical Reviews 13 (3) Current Issue. DOI: https://doi.org/10.1007/s12551021-00799-5

Swiatlowska P. and Iskratsch T. (2021) Announcing the call for the Special Issue on "Cardiovascular mechanobiology - a special issue to look at the state of the art and the newest insights into the role of mechanical forces in cardiovascular development, physiology, and disease" Biophysical Reviews. 13(3) Current Issue. DOI: https://doi. org/10.1007/s12551-021-00800-1

Tame, J.R. (2019). Approaches to entropy. Springer Singapore. ISBN: 978-981-13-2315-7

Tame J.R.H. (2021) Biophysical reviews 'meet the editor series'-Jeremy R. H. Tame. Biophysical Reviews 13(3). Current Issue. https://doi. org/10.1007/s12551-021-00798-6

Vasilaki D., Bakopoulou A., Tsouknidas A., Johnstone E. and Michalakis K. (2021) Biophysical interactions between components of the 
tumor microenvironment promote metastasis. Biophysical Reviews 13(3). https://doi.org/10.1007/s12551-021-00811-y

Welton T (2018) Ionic liquids: a brief history. Biophysical Reviews 10: 691-706. https://doi.org/10.1007/s12551-018-0419-2

Yakushevich L.V. and Krasnobaeva L.A. (2021) Ideas and methods of nonlinear mathematics and theoretical physics in DNA science: the McLaughlin-Scott equation and its application to study the DNA open states dynamics. Biophysical Reviews 13 (3) Current Issue. DOI: https://doi.org/10.1007/s12551-021-00801-0
Zidovska A (2020) The rich inner life of the cell nucleus: dynamic organization, active flows, and emergent rheology. Biophysical Reviews. 12:1093-1106. https://doi.org/10.1007/s12551-02000761-x

Publisher's note Springer Nature remains neutral with regard to jurisdictional claims in published maps and institutional affiliations. 